\title{
Cystathionine $\beta$-Synthase Deficiency: Differences in Thermostability between Normal and Abnormal Enzyme from Cultured Human Cells
}

\author{
LYNN D. FLEISHER, ${ }^{(18)}$ RICCARDO C. LONGHI, HARRIS H. TALLAN, AND GERALD E. GAULL \\ Department of Human Development and Genetics, New York State Institute for Basic Research in Mental \\ Retardation, Staten Island; and Department of Pediatrics and Clinical Genetics Center, Mount Sinai School of \\ Medicine of the City University of New York, New York, USA
}

\begin{abstract}
Summary
The thermostability of cystathionine $\beta$-synthase and the effect of pyridoxal phosphate (PLP) and other $B_{6}$ vitamers on this thermostability were studied in extracts of cultured skin fibroblasts from normal subjects, from heterozygotes for synthase deficiency, and from patients with homocystinuria due to synthase deficiency.

Incubation of crude extracts of normal fibroblasts at $55^{\circ}$ (preincubation) for short periods prior to assay consistently resulted in an increase of cystathionine synthase activity (activation) that reached a maximum at 2 min (Fig. 1). Further preincubation resulted in inactivation. Addition of $0.4 \mathrm{mM}$ PLP to the preincubation mixture resulted in greater activation that reached a maximum at 3-5 min. The subsequent inactivation phase proceeded at a slower rate than had occurred in the absence of PLP, resulting in a doubling of the half-life of thermal inactivation at $55^{\circ}$. PLP was the only one of the $B_{6}$ vitamers to have a protective effect.

No significant activation of synthase was observed when extracts of fibroblasts from synthase-deficient patients were preincubated at $55^{\circ}$. Cells from eight patients were studied: extracts from those of four patients demonstrated activity too low to permit measurement of thermostability; extracts of cells from two patients were less thermostable than those from control subjects and showed a protective effect of PLP; extracts of cells from two other patients (sibs) showed very high heat stability in the absence of PLP, but significant inactivation of synthase in the presence of the coenzyme (Fig. $2, A$ and $B$ ).

Three patterns of response to heating were observed with extracts of fibroblasts from seven obligate heterozygotes (Fig. 3): 1) no activation; 2) activation with and without prior addition of PLP to the preincubation mixture; and 3) activation only in the presence of PLP. The half-life of inactivation at $55^{\circ}$ of the extracts from heterozygotes was similar to that seen in extracts from control subjects.

Synthase from cultured long term lymphoid cells also showed activation followed by inactivation when preincubated at $55^{\circ}$, as well as protection by PLP.
\end{abstract}

\section{Speculation}

Heat-induced activation of cystathionine synthase is a physical characteristic of the normal enzyme molecule which is altered in enzyme from patients and from some heterozygotes for synthase deficiency. Although in vivo vitamin $B_{6}$ therapy restores the ability of hepatic synthase from patients to be activated, this restoration appears not to be the result of a direct stabilizing effect of the coenzyme PLP on the apoenzyme molecule. Furthermore, since PLP does not consistently protect enzyme from patients against heat inactivation in vitro, the increase of hepatic synthase activity observed in some patients receiving megavitamin therapy may not be mediated by a protective or stabilizing effect of the coenzyme.

The precise nature of the mutation(s) responsible for cystathionine $\beta$-synthase deficiency is not known. However, we recently demonstrated a qualitative difference in a physical property of hepatic synthase from affected individuals, i.e., the response to heat, which is corrected by vitamin $B_{6}$ therapy (10). Extracts of liver from normal individuals had increased cystathionine synthase activity after brief incubation at $55^{\circ}$ before assay (preincubation). Heat-induced activation was observed also in extracts of liver obtained from heterozygotes for synthase deficiency, but occurred in extracts from patients only during vitamin $B_{6}$ therapy. These findings suggested that in patients with homocystinuria due to cystathionine synthase deficiency this enzyme is structurally altered. Whether or not the mechanism of action of the vitamin involved a direct effect on the synthase molecule remained unanswered.

These results led us to investigate further the thermostability of cystathionine synthase and the effects of the in vitro addition of PLP, the coenzymatically active form of vitamin $B_{6}$, using cultured skin fibroblasts from normal subjects, heterozygotes, and patients with cystathionine synthase deficiency.

\section{MATERIALS AND METHODS}

Skin from the inner surface of the forearm was taken for culture. Informed consent was obtained in writing. Fibroblast cultures were established and maintained according to standard tissue culture procedures. Standard growth medium for diploid cells containing $0.5 \mathrm{mg}$ pyridoxine and $0.5 \mathrm{mg}$ pyridoxal/liter was used for most studies. In some experiments medium lacking both of the $B_{6}$ vitamers was used; in other experiments the medium was supplemented with 50 or $100 \mathrm{mg}$ pyridoxine/liter. Care was taken to assure that all cultures were harvested at the same stage oî confluence. After reaching confluence the cultures were fed, and harvested 3 days later. Lymphoid cell lines were established according to the technique of Beratis and Hirschhorn (1). Cell pellets were washed with saline and stored in liquid nitrogen until assayed, at which time they were lysed in distilled water using a Branson Sonifier with microtip.

Cell extracts were incubated before assay (preincubation) at $55^{\circ}$ (or other temperatures as noted) for varying lengths of time either with or without $0.4 \mathrm{mM}$ PLP (final volume $270 \mu \mathrm{l}$ ). PLP was then added where previously omitted in order to equalize the concentration present during the assay. The assay procedure is based on the direct measurement, on an automatic amino acid analyzer, of cystathionine formed in the reaction (4). The assay 
conditions for maximal enzymatic activity of cultured cell extracts have been reported previously (3).

Enzymatic activity is expressed as nanomoles of cystathionine formed $/ \mathrm{mg}$ protein $/ \mathrm{h}$. Protein concentrations were determined according to the method of Lowry et al . (11).

\section{RESULTS}

Incubation of normal fibroblast lysate at $55^{\circ}$ for short periods of time prior to assay (preincubation) resulted in an increase of cystathionine synthase activity that reached a maximum at 2 min (Fig. 1). After this initial "activation" phase, activity decreased with further preincubation. In the presence of $0.4 \mathrm{mM}$ PLP, preincubation resulted in activation with a maximum at 3-5 min. The subsequent inactivation proceeded at a slower rate than in the absence of PLP, resulting in a half-life of thermal inactivation of the enzyme in the presence of PLP that was twice that observed without addition of the coenzyme (Fig. 1, inset). The protective effect of PLP also is shown by the residual activity after $15 \mathrm{~min}$ of preincubation at $55^{\circ}$, which is twice as high in the presence of PLP as it is in its absence.

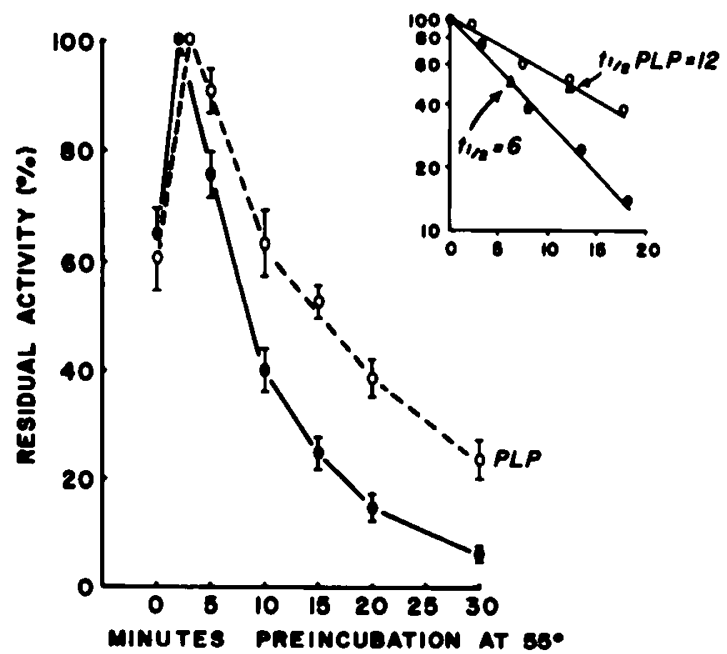

Fig. 1. The effect of preincubation at $55^{\circ}$ on the activity of cystathionine synthase in extracts of cultured human skin fibroblasts; $100 \%$ represents the maximal activity. ๑: preincubation without added PLP; $O$ : preincubation in presence of $0.4 \mathrm{mM}$ PLP. The inset shows the halflife (in minutes) of thermostability $(\mathbf{A})$ of the enzyme preincubated at $55^{\circ}$ with and without addition of $0.4 \mathrm{mM}$ PLP. The abscissa of the inset represents minutes from the point of maximal activity.

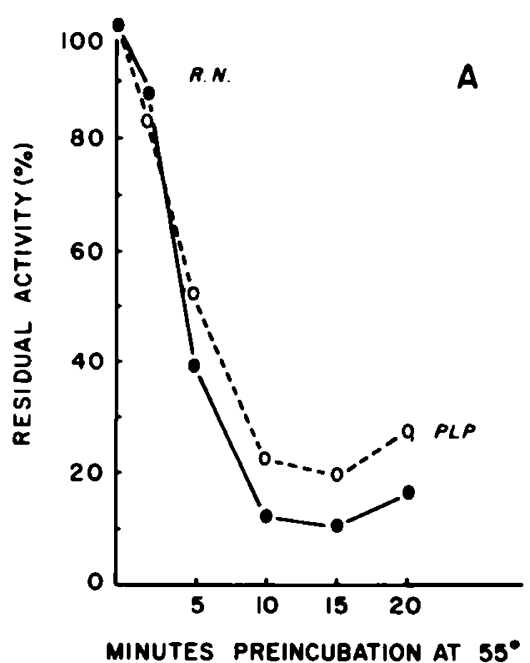

Lysate from normal fibroblasts was preincubated at $55^{\circ}$ for 15 min in the presence of each of the $B_{6}$ vitamers. The only vitamer to show a significant protective effect was PLP. None of the vitamers, including PLP, had any effect on the specific activity ( 0 time value) of the enzyme from any of the subjects.

Preincubation of the control fibroblast lysates at temperatures below $55^{\circ}$ resulted in less well defined patterns of activation and inactivation. Preincubation at $65^{\circ}$ produced immediate inactivation of the enzyme.

When lysates of fibroblasts derived from synthase-deficient patients were preincubated under the same conditions as those used for lysates from controls, no significant activation was observed. Fibroblast extracts from eight patients were studied: four (two responsive to $B_{6}$, two unresponsive to $B_{6}$ ) had such low enzymatic activity (less than $0.6 \mathrm{nmol} / \mathrm{mg}$ protein $/ \mathrm{hr}$ ) that no conclusions could be drawn regarding thermostability. Of the remaining four (all responsive to $\mathrm{B}_{6}$ ), one was less heat stable than the control subjects (Fig. $2 A$ ), both without and with addition of PLP to the preincubation mixture (half-lives during thermal inactivation of 4.5 and $5.5 \mathrm{~min}$, respectively, as compared to 6 and $12 \mathrm{~min}$, respectively, in control subjects). The protective effect of PLP was shown by a residual activity after $15 \mathrm{~min}$ of preincubation which is twice as high in the presence of PLP as it is in its absence. Results with extracts of fibroblasts from a second patient were similar. However, extracts of fibroblasts from the other two patients (sibs) had strikingly different properties in two respects (Fig. $2 B$ ). First, the enzyme was extremely heat stable, retaining $80 \%$ of the initial activity after $10 \mathrm{~min}$ of preincubation at $55^{\circ}$. Second, when PLP was added before preincubation, the enzyme was less thermostable, the activity decreasing sharply to less than $10 \%$ of the initial value after $10 \mathrm{~min}$ at $55^{\circ}$.

With fibroblast extracts from seven unrelated heterozygotes (Fig. 3), three patterns of heat response were observed. In one type no activation was observed; in the second type activation was observed with and without addition of PLP to the preincubation mixture; in the third type activation was observed only in the presence of PLP. The half-lives of thermostability of the enzyme and the activities remaining after $15 \mathrm{~min}$ of preincubation, both with and without the addition of PLP, were similar to those found in the control subjects.

When cells were grown in medium deficient in pyridoxine or supplemented $100-$ or 200 -fold the concentration normally present, cell growth was not affected, and neither a change in enzymatic activity nor a different thermostability pattern was observed with cell extracts from any of the subjects.

Synthase activation followed by inactivation after preincubation at $55^{\circ}$ was observed also in lysates of normal long term

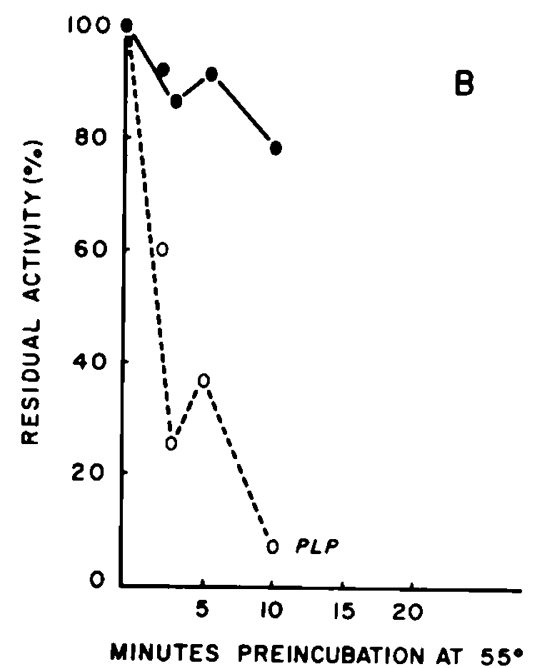

Fig. 2. Thermostability of cystathionine synthase in extracts of skin fibroblasts from two patients with synthase deficiency. $\bullet$ : preincubation at $55^{\circ}$ without added PLP; O: preincubation in the presence of 0.4 mM PLP. 


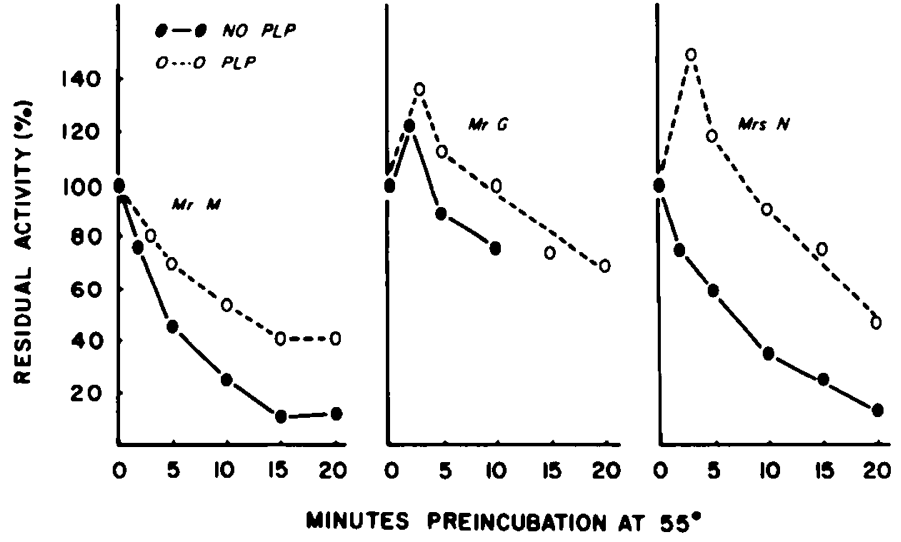

Fig. 3. Thermostability of cystathionine synthase in extracts of skin fibroblasts from heterozygotes for synthase deficiency. $\bullet$ : preincubation at $55^{\circ}$ without added PLP; $\bigcirc$ : preincubation in the presence of $0.4 \mathrm{mM}$ PLP.

lymphoid cells. Addition of $0.4 \mathrm{mM}$ PLP resulted in greater activation and an increased thermostability of the enzyme.

\section{DISCUSSION}

We recently have reported the heat-induced activation of cystathionine synthase in extracts from normal human liver (10). This phenomenon occurred also in extracts of liver from heterozygotes for synthase deficiency, but could be observed in extracts from pyridoxine-responsive patients with synthase deficiency only during megavitamin treatment. We suggested that activation represents an expression of the ability of the normal enzyme to undergo heat-induced conformational change (10). The inability of the abnormal enzyme to be activated by heat suggested an altered molecular structure, and was thought to be a property by which normal enzyme and that from deficient individuals can be distinguished qualitatively. Moreover, in vivo administration of vitamin $B_{6}$, in restoring the activation phenomenon, appeared to have an effect on the in vitro behavior of the enzyme.

We continued our investigations in cultured skin fibroblasts because of their greater availability. Enzyme from normal fibroblasts was activated by heat, whereas enzyme from patients' fibroblasts was not. Since it had been shown that activation by heat could be observed in hepatic extracts from patients only during pyridoxine therapy, the effect of PLP (the coenzymatically active form of pyridoxine) on enzyme from patients was investigated. Even with prior addition of PLP to the preincubation mixture, however, activation of synthase was not observed in fibroblast lysates from any of the patients. Thus, the restoration of heat-induced activation produced in hepatic synthase of patients by pyridoxine therapy in vivo is not mediated by a direct effect of PLP on the enzyme molecule. Either synthesis of new synthase molecules, which have the capability to be activated by heat, occurred during $B_{6}$ treatment, or such treatment affected another reaction which, in turn, mediated the activation. Either of these general possibilities could account for the difference in this regard between the effects of in vivo $B_{6}$ therapy and in vitro addition of PLP.

After the initial activation phase, synthase from fibroblasts both of normal subjects and of heterozygotes undergoes inactivation upon continued preincubation at $55^{\circ}$. This process of heat-induced inactivation can be retarded greatly by addition of PLP before preincubation. There was sufficient synthase activity in extracts of fibroblasts from four patients to permit investigation of thermostability; two different responses to heating were observed. Enzyme extracts from two unrelated, $B_{6}$-responsive patients were less thermostable than enzyme extracts from control subjects, as demonstrated by the shorter half-life of thermostability of patients' enzyme. The increased thermolability found in these two patients resembles that found by Kim and Rosenberg (8) in their case. The residual activity after $15 \mathrm{~min}$ of preincubation at $55^{\circ}$ was doubled by addition of PLP to extracts of fibroblasts from these two patients. Two other patients, $\mathrm{B}_{6-}$ responsive sibs, demonstrated a different and quite unexpected, response to heating. Enzyme extracts from both sibs possessed great heat stability, demonstrating only $20 \%$ loss of activity during $10 \mathrm{~min}$ of preincubation at $55^{\circ}$. Even more surprising was the finding that addition of PLP before preincubation actually accelerated the heat-induced inactivation, rather than protecting against it. The variable responses to heat of synthase and the effect of PLP on this response provide further evidence of the genetic heterogeneity of synthase deficiency. Such heterogeneity might explain the apparent discrepancy between the present results (that addition of PLP has the same or greater effect on synthase from normal subjects than on synthase from patients) and those of Kim and Rosenberg (8) (that PLP has a greater protective effect on synthase from patients than on synthase from normal subjects).

The observation of different patterns of response to heat within the heterozygote group is further evidence of genetic heterogeneity in synthase deficiency (5). There is not yet enough data from complete families to judge whether or not any correlation can be made between heterozygotes and homozygotes from the same family. This variation in response to heat is consistent with other lines of evidence that hepatic cystathionine synthase, both in the rat and in man, is not a monomer $(6,9)$. Furthermore, it is known that heterozygotes for synthase deficiency demonstrate only $20-25 \%$ of the mean control activity $(2,3,5,15)$, rather than the $50 \%$ expected on the basis of the simple gene-dose relationship observed with monomeric enzymes. The present results lend further support to the suggestion $(3,15)$ that in the heterozygote the normal polypeptide chains are influenced by the abnormal polypeptide chains via combination into multimeric enzyme units. With such multimeric enzymes, whether they represent the products of multiple alleles or multiple loci for synthase, a broad spectrum of response to heat might be anticipated.

Since megavitamin therapy with pyridoxine restores the activation phenomenon in liver extracts from $B_{6}$-responsive patients (10), and PLP does not have this effect in vitro on fibroblasts, we investigated the effects of the other $B_{6}$ vitamers on synthase thermostability. Activation was not observed in extracts of patients' fibroblasts, either unsupplemented or with addition of any of the $B_{6}$ vitamers. As expected, activation was shown by normal fibroblast extracts in the absence of $B_{6}$, as well as in the presence of any of the six vitamers. The only vitamer to offer protection against heat inactivation was PLP.

Heat-induced activation of cystathionine synthase has not been reported by other workers who have examined the effects of heat on cystathionine synthase $(7,8,12)$; however, their experiments and ours were done in different ways. The studies of Mudd $e t$ al. (12) were carried out at a temperature of $59^{\circ}$ with liver extracts pretreated with trypsin in order to activate the synthase; either or both factors may account for the absence of heat activation in their experiments. Kim and Rosenberg (8) conducted thermostability studies on fibroblasts, using partially purified extracts. Although we did not attempt to purify extracts of cultured skin fibroblasts, activation was present in partially purified (14) extracts of human liver (10). Recently, Griffiths and Tudball (7) have reported the effect of temperature on cystathionine synthase activity in extracts of cultured fibroblasts. They preincubated for a minimum of $2 \mathrm{hr}$, rather than the 3-5 min necessary for maximal heat activation; therefore, enzyme activation could not have been seen.

Griffiths and Tudball (7) report that $100 \mathrm{mg}$ pyridoxine/liter of culture medium prevented cell growth, but that $25-50 \mathrm{mg}$ / liter resulted in increased synthase activity in cells from their patient $(25 \mathrm{mg} / \mathrm{liter}$ resulted in slightly increased activity in cells 
from their control subject). These results are not consistent with those we have presented here and are not consistent with those of other investigators (13). Griffiths and Tudball (7) present evidence from only one normal and one abnormal cell line; therefore, the discrepancy could be an apparent difference due to genetic heterogeneity.

\section{CONCLUSION}

Heat-induced activation appears to be a general characteristic of cystathionine synthase from various tissue sources, as we have demonstrated activation of cystathionine synthase in partiallypurified extracts of human liver, in crude extracts of human liver, brain, cultured skin fibroblasts, and lymphoid-cell lines, and in crude extracts of liver and brain of rat and monkey (10, unpublished observations). This phenomenon does not occur in extracts of liver or of cultured skin fibroblasts from untreated patients with synthase deficiency, suggesting a structural alteration in the enzyme synthesized by the mutant gene. Since vitamin $B_{6}$ therapy restores activation in hepatic synthase of patients, whereas the $B_{6}$ vitamers do not have this effect upon addition in vitro, it would appear that this phenomenon is not the result of a direct effect of the coenzyme on the apoenzyme molecule. Pyridoxal phosphate, but no other $\mathbf{B}_{6}$ vitamer, increases the thermostability of cystathionine synthase from fibroblast lysates of normal individuals and from some, but not all, synthase-deficient individuals. This is further evidence of genetic heterogeneity in this disease.

\section{REFERENCES AND NOTES}

1. Beratis, N., and Hirschhorn, K.: Procedure for establishment of long term lymphoid cell lines by using PHA and HLV. In: D. Bergsma: Long-term Lymphocyte Cultures in Human Genetics, p. 247, Birth Defects: Original Article Series, Vol. 9, (The National Foundation, White Plains, NY, 1973).

2. Finkelstein, J. D., Mudd, S. H., Irreverre, F., and Laster, L.: Homocystinuria due to cystathionine synthase deficiency: The mode of inheritance. Science, 146: 785 (1964)

3. Fleisher, L. D., Tallan, H. H., Beratis, N. G., Hirschhorn, K., and Gaull, G.
E.: Cystathionine synthase deficiency: Heterozygote detection using cur tured skin fibroblasts. Biochem. Biophys. Res. Commun., 55: 38 (1973).

4. Gaull, G. E., Rassin, D. K., and Sturman, J. A.: Enzymatic and metabolic studies in homocystinuria: Effects of pyridoxine. Neuropädiatrie, l: 199 (1969).

5. Gaull, G. E., and Sturman, J. A.: Vitamin $B_{\mathbf{a}}$ dependency in homocystinuria. Brit. Med. J., 3: 532 (1971)

6. Griffiths, R., and Tudball, N.: The molecular defect in a case of (cystathionine $\beta$-synthase)-deficient homocystinuria. Eur. J. Biochem., 74: 269 (1974).

7. Griffiths, R., and Tudball, N.: Studies on the use of skin fibroblasts for the measurement of cystathionine synthase activity with respect to homocystinuria. Clin. Chim. Acta, 73: 157 (1976).

8. Kim, Y. J., and Rosenberg, L. E.: On the mechanism of pyridoxine responsive homocystinuria. II. Properties of normal and mutant cystathionine $\beta$-synthase from cultured fibroblasts. Proc. Natl. Acad. Sci. U. S. A., 71: 4821 (1974).

9. Kimura, H., and Nakagawa, H.: Studies on cystathionine synthase: characteristics of purified rat liver enzyme. J. Biochem., 69: 711 (1971).

10. Longhi, R. C., Fleisher, L. D., Tallan, H. H., and Gaull, G. E.: Cystathionine $\beta$-synthase deficiency: A qualitative abnormality of the deficient enzyme modified by vitamin B, therapy. Pediat. Res., 11: 100 (1977).

11. Lowry, O. H., Rosebrough, N. J., Farr, A. L., and Randall, R. J.: Protein measurement with the Folin phenol reagent. J. Biol. Chem., 193: 275 (1951).

12. Mudd, S. H., Edwards, W. A., Loeb, P. M., Brown, M. S., and Laster, L. Homocystinuria due to cystathionine synthase deficiency: The effect of pyridoxine, J. Clin. Invest., 49: 1762 (1970).

13. Seashore, M. R., Durant, J. L., and Rosenberg, L. E.: Studies of the mechanism of pyridoxine-responsive homocystinuria. Pediat. Res., 6: 187 (1972).

14. Tallan, H.H., Pascal, T. A., Schneidman, K., Gillam, B. M., and Gaull, G. E.: Homolanthionine synthesis by human liver cystathionase. Biochem. Biophys. Res. Commun., 43: 303 (1971).

15. Uhlendorf, B. W., Conerly, E. B., and Mudd, S. H.: Homocystinuria: Studies in tissue culture. Pediat. Res., 7: 645 (1973).

16. This research was supported in part by New York State Department of Mental Hygiene; NIH Clinical Genetics Center Grant GM-19443; NIH Grant RR 00071, Division of Research Resources, General Clinical Research Center Branch; and the Lalor Foundation.

17. We would like to thank Mrs. Susan Sansevero for expert technical assistance.

18. Requests for reprints should be addressed to: Lynn D. Fleisher, Ph.D., Department of Human Development and Genetics, New York State Institute for Basic Research in Mental Retardation, 1050 Forest Hill Road, Staten Island, New York 10314 (USA)

19. Received for publication April 5, 1977.

20. Accepted for publication July 13, 1977. 